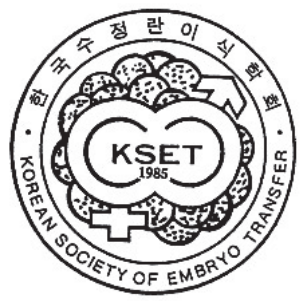

\title{
Comparison of Spermatozoa Recovery Methods on Cauda Epididymal Sperm of Hanwoo Bulls
}

Sung-Sik Kang, Ui-Hyung Kim, Min-Hyeong Jeon, Myung-Suk Lee and Sang-Rae $\mathrm{Cho}^{+}$

Hanwoo Research Institute, NIAS, RDA, Pyeongchang, Kangwondo, 25340 Republic of Korea

\section{Abstract}

In this study, two epididymal spermatozoa recovery methods in relation to sperm number, motility, viability and acrosome reaction were examined. Seven bulls were castrated and 7 testicles with epididymides were transferred to the laboratoy. Epididymis in each bull was randomly used for flushing and mincing methods with semen extender (Optixcell, IMV, France). The recovered spermatozoa with adjusted sperm concentration to $40 \times 10^{6}$ cells $/ \mathrm{mL}$ was diluted with optixcell and cryopreserved. In experiment 1 , the difference in the total number of spermatozoa using flushing and mincing methods was insignificant (2570.0 and $2505.2 \times 10^{6}$ cells $/ \mathrm{mL}$, respectively). For experiment 2 , the percentage of motile spermatozoa and motility parameters between flushing and mincing methods were studied through the use of sperm class analyzer after frozen-thawing. The percentage of total motile sperm between flushing and mincing methods was almost the same with $89.5 \pm 12.8$ and $91.4 \pm 7.9 \%$, respectively. The same is the case with experiment 3 wherein the viability and acrosomal integrity of frozen-thawed epididymal spermatozoa by flushing and mincing was insignificantly different. The results from the study showed that both flushing and mincing methods can be used for epididymal spermatozoa recovery in bull.

Received : 21 October 2018

Revised : 8 November 2018

Accepted : 2 December 2018
Key Words : Bull, Epididymal spermatozoa, Motility, Recovery method 


\section{INTRODUCTION}

The artificial insemination (AI) technology facilitates rapid improvement of livestock and beef industries (Foote, 2002). In the field, AI usually involves collection of bull semen by artificial vagina (AV) and electroejaculation (EJ) methods (Rego et al., 2015). The AV method requires training of bulls while EJ method which is used as an alternative does not need training of bulls (Jimenez-Rabadan et al., 2012). Animals with dead (Prieto et al., 2014) or erectile dysfunction (Kapoor et al., 2015) are not suitable for semen collection by EJ or AV methods. On the other hand, cauda epididymis has a role in storage of matured spermatozoa until ejaculation (Jones, 2004). Thus, spermatozoa recovery from cauda epididymis is used as an alternative of EJ or AV methods for gametes preservation of dead animals and animal sexual disorders. Numerous methods were utilized to recover epididymal spermatozoa namely cutting, floating, mincing, and flushing of epididymal spermatozoa for dead domestic and wild species (Fickel et al., 2007). In cutting method, used in bull (Martins et al., 2007) and goat (Jindal, 1984), isolated epididymis from testis was cut numerous times and spermatozoa was recovered by squeezing of epididymis. Floating method was applied in bull (Turri et al., 2012), canine (Yu and Leibo, 2002), feline (Thuwanut et al., 2010; Filliers et al., 2008), ram (Lone et al., 2011), and in stallion (Cary et al., 2004). In this method, sliced or incised epididymis was placed in recovery fluid in petri dish or tube for several minutes. Motile spermatozoa will swim out to fluid from tubules of cauda epididymis and fluid with spermatozoa will be recovered. For mincing method in bull (Kang et al., 2016), feline (Vernocchi et al., 2014), and stallion (Neuhauser et al., 2013), isolated cauda epididymis was minced finely and fluid with spermatozoa was immediately recovered. And lastly for flushing method, syringe with semen recovery fluid was connected to the vas deferens of the epididiymis of boar (Rath and Niemann, 1997), bull (Papa et al., 2015), ibex red deer (Santiago-Moreno et al., 2009), and rabbit (Brackett et al., 1978). Pressure was applied into epididymis and several incisions was made to cut tubules in cauda epidydimis thereby releasing the spermatozoa. Epididymal spermatozoa recovery methods affects sperm motility, sperm concentration, and quantity of debris and blood contamination. Thus, efficiency of recovery methods on epididymal spermatozoa were compared in several species, for example the cutting and mincing methods on sperm concentration and blood contamination on Iberian red deer (Martinez-Pastor et al., 2006). Influence of flushing and floating methods on sperm motility were also compared in bull (Turri et al., 2012) and stallion (Cary et al., 2004). No studies were done yet on the comparison of the two methods, thus this study examined the efficacy of flushing and mincing methods on epididymal spermatozoa recovery in bull. The spermatozoa of cauda epididymis was retrieved by flushing and mincing methods and was frozen using the semen freezing media. The motility and acrosomal membrane integrity of frozen-thawed spermatozoa were also examined.

\section{MATERIALS AND METHODS}

\section{Ethics of animal experimentation}

The cows used in this study were handled in accordance to the guidelines (grade D) of the National Institute of Animal Science (NIAS), Rural Development Administration, Cheonjoo, Republic of Korea. Procedures done were also approved by the animal experiment and ethics committee of the NIAS.

\section{Castration and recovery of epididymis}

Seven testicles with epididymides were castrated from seven Hanwoo bulls (mean \pm standard deviation, months of age $=15.1 \pm 0.2$, scrotal circumference $(\mathrm{cm})=31.6 \pm 1.1$, and body weight $(\mathrm{kg})=$ 391.1 \pm 16.6). The castration of bulls was carried out until December 2017 at the Hanwoo Research Institute, NIAS, Pyeongchang, Republic of Korea. For general anesthesia of bull, $1.0 \mathrm{~mL}$ per $100 \mathrm{~kg}$ of xylazine hydrochloride (Rompun, Bayer, Republic of Korea) was injected into jugular vein of bull. After 5 to 15 minutes of injection, body, legs and head of bull were fixed with rope. And scrotal circumference was estimated with scrotal measuring tape and skin of testis was incised by scalpel. Testis with epididymides was recovered and surgical site was sutured. Twenty $\mathrm{mL}$ of dexamethasone disodium phosphate (Dexolone-20, SamyangAnifarm, Republic of Korea) and $20 \mathrm{~mL}$ of antibiotics (G.C.GPS-INJ., Green Cross Veterinary, Republic of Korea) were injected into the intramuscle. And testis with epididymides was transported to the laboratory within the first hour. In the laboratory, tunica albuginea of testicles was removed and testicular weight, length, width, and circumference were measured. Epididymis with vas deferens was isolated from testis and blood vessels on surface of cauda epididymis were removed. Random selection was done to determine if the epididymis will be processed by flushing or mincing method. 


\section{Spermatozoa recovery by flushing method}

A 26 gauge needle connected with $10 \mathrm{~mL}$ syringe was inserted into the duct of vas deferens. The connecting part of the needle and vas deferens duct was fixed with forceps. About 12-15 incisions of cauda epididymis were made and pre-warmed semen freezing medium (OptixCell, IMV Technologies, France) was flushed in a $100 \mathrm{~mm}$ dish (Falcon).

\section{Spermatozoa recovery by mincing method}

The recovery of cauda epididymis spermatozoa by mincing adopted the procedure conducted by Kang et al., in 2016 with slight modification. Isolated cauda epididymis was minced using blades (No.21, AILEE, Korea) and surgical scissors in a $100 \mathrm{~mm}$ dish. Minced cauda epididymis tissues were incubated with $10 \mathrm{~mL}$ of semen freezing medium for 15 minutes at $25^{\circ} \mathrm{C}$. Sperm suspension was recovered by filtration using a cell strainer (100 $\mu \mathrm{m}$ nylon mesh, Falcon).

\section{Semen freezing}

Semen freezing was also performed by Kang et al., (2016) procedure with slight modification. Sperm concentration was adjusted to $40 \times 10^{6}$ cells $/ \mathrm{mL}$ with semen freezing media and preserved at $4{ }^{\circ} \mathrm{C}$ for 4 hours. Semen dilution was loaded to 0.5 $\mathrm{mL}$ straw, preserved at $3 \mathrm{~cm}$ from liquid nitrogen $\left(\mathrm{LN}_{2}\right)$ for 14 minutes, and plunged into $\mathrm{LN}_{2}$.

\section{Measurement of sperm motility}

The measurement of sperm motility was done by also following a study of Kang et al., (2015). Semen was thawed at $37^{\circ} \mathrm{C}$ for 40 seconds and transferred to a $1.5 \mathrm{~mL}$ tube. Three $\mu \mathrm{L}$ of semen was placed onto 4-chamber slides with a depth of $20 \mu \mathrm{m}$ (Art. No. SC-20-01-04-B, Leja, Nieuw-Vennep, Netherlands). At least 1000 sperm in 4-6 fields in a chamber were classified into motile and dead sperm. The percentage of motile sperm and motility parameters such as straight line velocity (VSL, $\mu \mathrm{m} / \mathrm{s}$ ), curvilinear velocity (VCL, $\mu \mathrm{m} / \mathrm{s}$ ), average path velocity (VAP, $\mu \mathrm{m} / \mathrm{s})$, linearity $(\mathrm{LIN}=\mathrm{VSL} / \mathrm{VCL} \times 100, \%)$, straightness $(\mathrm{STR}$, $\%$ ), wobble (WOB, \%), flagellar beat cross frequency (BCF, $\mathrm{Hz})$, and amplitude of lateral head (ALH, $\mu \mathrm{m})$ were evaluated using CASA system (Sperm Class Analyzer, MicroOptic, Spain). Motile sperm with a VSL of $\geq 25 \mu \mathrm{m} / \mathrm{sec}$ were selected since having a VSL of less than $25 \mu \mathrm{m} / \mathrm{sec}$ will not be able to penetrate the oocyte according to Aitken (1985) and Holt et al., (1985).

\section{Staining of frozen-thawed epididymal spermatozoa and evaluation of sperm viability and acrosomal membrane integrity}

The staining and fixing solutions were prepared using the previous study of Kovacs and Foote, (1992) with minimal modification. Viability testing solution consisted of $0.25 \%$ trypan blue (Sigma-Aldrich, cat No. T6146) in $0.81 \% \mathrm{NaCl}$ (w/v) while fixing solution consisted of $86 \mathrm{~mL}$ of $1 \mathrm{~N} \mathrm{HCl}, 14 \mathrm{~mL}$ of $1 \mathrm{~N}$ formaldehyde solution (Sigma-Aldrich, cat No. 252549), and $0.2 \mathrm{~g}$ neutral red (Sigma-Aldrich, cat No. N4638). Meanwhile, acrosome testing solution consisted of $7.5 \%$ Giemsa solution (Merck, cat No. 109204100) in distilled water. Twenty $\mu$ of spermatozoa dilution was mixed with pre-warmed $20 \mu$ of viability solution while another ten $\mu$ l of mixed solution was mounted on a slide glass and smeared. Slides were air dried, fixed with fixing solution for 5 minutes, washed with tap water, air dried at RT, and stained with acrosome testing solution for 12 hours. For the evaluation of sperm viability, morphology, and acrosome integrity of sperm, previous study of Kovacs and Foote (1992) was used. From each semen sample, more than 200 sperms in a slide glasses were counted by bright field microscopy at magnification $400 \times$. The viability and acrosome integrity of sperm were also evaluated. Unlike live sperm which were not stained, dead sperm were stained with trypan dark blue at posterior region. On the other hand, normal acrosome of sperm was stained with Giemsa (violet) while abnormal or damaged acrosome was not stained.

\section{STATISTICAL ANALYSIS}

Testis characters, recovered sperm concentration and total number of spermatozoa, percentage of motile, motility parameters, viability and acrosomal integrity of spermatozoa among flushing and mincing groups were compared using one-way ANOVA, followed by the Duncan test for post hoc analysis. All analyses were performed using SAS (statistical analysis system for software version 9.2).

\section{RESULTS AND DISCUSSION}

Numerous studies were done on epididymal spermatozoa recovery methods from cauda epididymis in wild and domestic animals. However, comparison of flushing and mincing methods 
Table 1. Testis characteristics and recovered spermatozoa concentration using flushing and mincing methods

\begin{tabular}{|c|c|c|c|c|c|c|c|}
\hline \multirow{2}{*}{$\begin{array}{l}\text { Recovery } \\
\text { methods (Rep.) }\end{array}$} & \multicolumn{4}{|c|}{$\begin{array}{c}\text { Testis Characteristics } \\
(\text { Mean } \pm \mathrm{SD})\end{array}$} & \multicolumn{3}{|c|}{ Sperm Recovered } \\
\hline & $\begin{array}{l}\text { Weight } \\
\text { (g) }\end{array}$ & $\begin{array}{l}\text { Length } \\
(\mathrm{cm})\end{array}$ & $\begin{array}{l}\text { Width } \\
(\mathrm{cm})\end{array}$ & $\begin{array}{l}\text { Circumference } \\
\qquad(\mathrm{cm})\end{array}$ & $\begin{array}{l}\text { Vol. } \\
(\mathrm{mL})\end{array}$ & $\begin{array}{l}\text { Sperm conc. } \\
\left(\times 10^{6} \text { cells } / \mathrm{mL}\right)\end{array}$ & $\begin{array}{l}\text { Total No. sperm } \\
\left(\times 10^{6} \text { cells }\right)\end{array}$ \\
\hline Flushing (7) & $221.0 \pm 12.0$ & $15.9 \pm 0.9$ & $5.7 \pm 0.3$ & $15.0 \pm 1.2$ & $63.3 \pm 28.0$ & $40.6 \pm 1.0$ & $2570 \pm 28.0$ \\
\hline Mincing (7) & $216.6 \pm 15.2$ & $16.0 \pm 0.9$ & $5.7 \pm 0.3$ & $14.9 \pm 1.1$ & $61.7 \pm 23.8$ & $40.6 \pm 1.5$ & $2505.2 \pm 35.7$ \\
\hline
\end{tabular}

for spermatozoa recovery of bull were not yet studied. Thus, in this study, the efficiency of flushing and mincing methods were compared using the following factors; recovered sperm number and motility, viability and acrosomal integrity of frozen-thawed spermatozoa. As shown in Table 1, testis characteristics were similar among flushing and mincing methods. Testicle size and scrotal circumference were positively correlated to sperm production in bull (Palasz et al., 1994) and ram (Elmaz et al., 2007). Results showed that similar number of sperm was recovered by flushing and mincing methods which is $2570.0 \times$ $10^{6}$ and $2505.2 \times 10^{6}$ cells, respectively. Thus, it can be concluded that condition of epididymal spermatozoa from cauda epididymis was similar and testis characteristics and method used will not influence the number of spermatozoa (Turri et al., 2012).

Table 2 and Table 3 also showed that values on total motility and motility parameters and viability and acrosomal membrane integrity of frozen-thawed spermatozoa using flushing and mincing methods were insignificantly different. However, a study of Hori et al., (2015), demonstrated that mincing methods have demerits of blood contamination from blood vessels in the surface of cauda epididymis and mixing of tissues from cauda epididymis. The blood contamination in epididymal spermatozoa dilution can induce increase in acrosome reaction and decrease in motility and viability (Martinez-Pastor et al., 2006). In this study, the indifference in the values may be due to clear removal of blood vessels on the surface of cauda epididymis. Meanwhile, a study of Martinez-Pastor et al., (2006) and Cary et al., (2004) found out that flushing method's use in the recovery of cauda epididymal spermatozoa in stallion is without blood contamination and tissue debris. Therefore, it is recommended that flushing method be used by well-trained practitioners since connecting and making incisions between needle and vas deferens are time consuming time and require technical skills. On the other hand, mincing methods is more appropriate for beginners due to easier collection of epididymal spermatozoa.

Several researches have been done to compare the type of semen extenders used for epididymal spermatozoa collection. Lopes et al., (2015) and Krishnakumar et al., (2011) differentiated the effect of Andromed and Tris egg yolk glycerol extender on bull epididymal spermatozoa. On the other hand, Neuhauser et al., (2018) compared stallion epididymal sperm motility using extenders such as skim milk, defined milk protein, egg yolk and caseinate extenders. In this study, only one semen extender (Optixcell) was utilized for epididymal spermatozoa collection

Table 2. Motility and motility parameters of frozen-thawed epididymal spermatozoa by flushing and mincing methods

\begin{tabular}{ccc}
\hline Recovery method (Rep.) & Flushing (35) & Mincing (35) \\
$\%$ of total motile sperm & $89.5 \pm 12.8$ & $91.4 \pm 7.9$ \\
$\%$ of motile sperm (VSL $\geq 25 \mu \mathrm{m} / \mathrm{s})$ & $40.9 \pm 10.0$ & $37.3 \pm 9.3$ \\
VCL $(\mu \mathrm{m} / \mathrm{s})$ & $135.8 \pm 23.1$ & $131.7 \pm 19.7$ \\
VSL $(\mu \mathrm{m} / \mathrm{s})$ & $50.4 \pm 3.7$ & $48.6 \pm 4.1$ \\
VAP $(\mu \mathrm{m} / \mathrm{s})$ & $76.5 \pm 9.1$ & $74.2 \pm 8.0$ \\
LIN $(\%)$ & $43.9 \pm 7.6$ & $43.6 \pm 6.5$ \\
STR $(\%)$ & $68.4 \pm 6.0$ & $68.1 \pm 5.0$ \\
WOB $(\%)$ & $61.6 \pm 5.2$ & $61.5 \pm 4.8$ \\
ALH $(\mu \mathrm{m})$ & $4.5 \pm 0.9$ & $4.4 \pm 0.8$ \\
BCF $(\mathrm{Hz})$ & $10.9 \pm 1.3$ & $10.5 \pm 1.2$ \\
\hline
\end{tabular}

Seven testes were used in both flushing and mincing groups. Five replicates of sperm motility and motility parameters in each bull were evaluated. Mean \pm SD. 
Table 3. Viability and acrosomal integrity of frozen-thawed epididymal spermatozoa by flushing and mincing methods

\begin{tabular}{ccccc}
\hline Recovery method (Rep.) & LIA & LDA & DIA & DDA \\
Flushing (35) & $71.7 \pm 6.3$ & $0 \pm 0$ & $23.9 \pm 3.8$ & $4.4 \pm 3.3$ \\
Mincing (35) & $72.4 \pm 7.3$ & $0.2 \pm 0.4$ & $23.8 \pm 6.5$ & $3.6 \pm 2.9$ \\
\hline
\end{tabular}

Seven testes were used in both flushing and mincing groups. Five replicates in each bull were evaluated. Mean \pm SD.

Live spermatozoa with intact acrosome (LIA), live spermatozoa with damaged acrosome (LDA), dead spermatozoa with intact acrosome (DIA), and dead spermatozoa with damaged acrosome (DDA).

thus there is no report on the effect of semen extenders on epididymal spermatozoa motility in Hanwoo bull. Therefore, it is recommended for future studies to examine the effect of semen extenders on increasing the recovered epididymal spermatozoa quality in Hanwoo bull. In conclusion, the results demonstrated that both of flushing and mincing methods are appropriate for recovery of epididymal spermatozoa.

\section{ACKNOWLEDGMENTS}

This study was funded by the 2018 Postdoctoral Fellowship Program of the Hanwoo Research Institute, RDA, Republic of Korea. It was also carried out with the support of the Cooperative Research Program for Agriculture Science \& Technology Development project titled "Improved technology to increase the efficiency of using the Hanwoo epididymal sperm", project PJ01197301, RDA, Republic of Korea.

\section{CONFLICT OF INTEREST}

None of the authors have a conflict of interest to declare.

\section{REFERENCES}

Aitken RJ. 1985. Diagnostic value of the zona-free hamster oocyte penetration test and sperm movement characteristics in oligozoospermia. Int. J. Androl., 8: 348-356.

Brackett BG, Hall JL and Oh YK. 1978. In vitro fertilizing ability of testicular, epididymal, and

ejaculated rabbit spermatozoa. Fertil. Steril., 29: 571-582.

Cary JA, Madill S, Farnsworth K, Hayna JT, Duoos L and Fahning ML. 2004. A comparison of electroejaculation and epididymal sperm collection techniques in stallions. Can. Vet. J., 45: 35-41.
Elmaz O, Cirit U and Dernir H. 2007. Relationship of testicular development with age, body weight, semen characteristics and testosterone in Kivircik ram lambs. S. Afr. J. Anim. Sci., 37: 269-274.

Fickel J, Wagener A and Ludwig A. 2007. Semen cryopreservation and the conservation of endangered species. Eur. J. Wildlife Res., 53: 81-89.

Filliers M, Rijsselaere T, Bossaert P, De Causmaecker V, Dewulf J, Pope CE and Van Soom A. 2008. Computer-assisted sperm analysis of fresh epididymal cat spermatozoa and the impact of cool storage (4 degrees C) on sperm quality. Theriogenology, 70: $1550-1559$.

Foote RH. 2002. The history of artificial insemination: Selected notes and notables. J. Anim. Sci., 80: 1-10.

Holt WV, Moore HD and Hillier SG. 1985. Computer-assisted measurement of sperm swimming speed in human semen: correlation of results with in vitro fertilization assays. Fertil. Steril., 44: 112-119.

Hori T, Atago T, Kobayashi M and Kawakami E. 2015. Influence of different methods of collection from the canine epididymides on post-thaw caudal epididymal sperm quality. J. Vet. Med. Sci., 77: 625-630.

Jimenez-Rabadan P, Ramon M, Garcia-Alvarez O, Maroto-Morales A, del Olmo E, Perez-Guzman MD., Bisbal A, Fernandez-Santos MR, Garde JJ and Soler A J. 2012. Effect of semen collection method (artificial vagina vs. electroejaculation), extender and centrifugation on post-thaw sperm quality of Blanca-Celtiberica buck ejaculates. Anim. Reprod. Sci., 132: 88-95.

Jindal SK. 1984. Sperm concentration in different segments of the goat epididymis. Theriogenology, 22: 545-551.

Jones R. 2004. Sperm survival versus degradation in the Mammalian epididymis: a hypothesis. Biol. Reprod., 71: 1405-1411.

Kang SS, Koyama K, Huang W, Yang Y, Yanagawa Y, Takahashi $\mathrm{Y}$ and Nagano M. 2015. Addition of D-penicillamine, hypotaurine, and epinephrine (PHE) mixture to IVF medium maintains motility and longevity of bovine sperm and enhances stable production of blastocysts in vitro. J. Reprod. Dev., 61: 
99-105.

Kang SS, Cho SR, Kim UH, Park CS, Kim HC, Chung KY, Lee SD, Jang S S, Jeon GJ, Kim S, Lee MSand Yang BC. 2016. Analysis of epididymal sperm from Korean native bull (Hanwoo) aged at 8 and 15 months before freezing and after thawing. J. Emb. Trans., 25: 201-206.

Kapoor MS, Khan SA, Gupta SK, Choudhary R and Bodakhe SH. 2015. Animal models of erectile dysfunction. J. Pharmacol. Tox. Met., 76: 43-54.

Kovacs A and Foote RH. 1992. Viability and acrosome staining of bull, boar and rabbit spermatozoa. Biotech. Histochem., 67: 119-124.

Krishnakumar S, Whiteside DP, Elkin B and Thundathil JC. 2011. Evaluation of an animal protein-free semen extender for cryopreservation of epididymal sperm from North American bison (Bison bison). Theriogenology, 76: 252-260.

Lone FA, Islam R, Khan MZ and Sofi KA. 2011. Effect of transportation temperature on the quality of cauda epididymal spermatozoa of ram. Anim. Reprod. Sci., 123: 54-59.

Lopes G, Soares L, Ferreira P and Rocha A. 2015. Tris-egg yolk-glycerol (TEY) extender developed for freezing dog semen is a good option to cryopreserve bovine epididymal sperm cells. Reprod. Domest. Anim., 50: 97-103.

Martinez-Pastor F, Garcia-Macias V, Alvarez M, Chamorro C, Herraez P, de Paz P and Anel L. 2006. Comparison of two methods for obtaining spermatozoa from the cauda epididymis of Iberian red deer. Theriogenology, 65: 471-485.

Martins CF, Rumpf R, Pereira DC and Dode MN. 2007. Cryopreservation of epididymal bovine spermatozoa from dead animals and its uses in vitro embryo production. Anim. Reprod. Sci., 101: 326-331.

Neuhauser S, Gosele P and Handler J. 2018. The effect of four different commercial semen extenders on the motility of stallion epididymal sperm. J. Equine. Vet. Sci., 62: 8-12.

Neuhauser S, Rheinfeld S and Handler J. 2013. Motility of fresh and frozen-thawed stallion sperm from three segments of the epididymal cauda and the Eleffect of post-haw seminal plasma addition on motility. J. Equine. Vet. Sci., 33: 942-949.

Palasz AT, Cates WF, Barth AD and Mapletoft RJ. 1994. The
Relationship between scrotal circumference and quantitative testicular traits in yearling beef bulls. Theriogenology, 42: 715-726.

Papa PM, Papa FO, Oliveira LA, Guasti PN, Castilho C and Giometti IC. 2015. Different extenders in the cryopreservation of bovine epididymal spermatozoa. Anim. Reprod. Sci., 161: 58-63.

Prieto MT, Sanchez-Calabuig MJ, Hildebrandt TB, Santiago-Moreno J and Saragusty J. 2014. Sperm cryopreservation in wild animals. Eur. J. Wildlife Res., 60: 851-864.

Rath D. and Niemann H. 1997. In vitro fertilization of porcine oocytes with fresh and frozen-thawed ejaculated or frozen-thawed epididymal semen obtained from identical boars. Theriogenology, 47: 785-793.

Rego JPA, Moura AA, Nouwens AS, McGowan MR and Boe-Hansen GB. 2015. Seminal plasma protein profiles of ejaculates obtained by internal artificial vagina and electroejaculation in Brahman bulls. Anim. Reprod. Sci., 160: 126-137.

Santiago-Moreno J, Astorga RJ, Luque I, Coloma MA, Toledano-Diaz A, Pulido-Pastor A, Gomez-Guillamon F, Salas-Vega R and Lopez-Sebastian A. 2009. Influence of recovery method and microbial contamination on the response to freezing-thawing in ibex (Capra pyrenaica) epididymal spermatozoa. Cryobiology, 59: 357-362.

Thuwanut P, Chatdarong K, Johannisson A, Bergqvist AS, Soderquist L and Axner E. 2010. Cryopreservation of epididymal cat spermatozoa: effects of in vitro antioxidative enzymes supplementation and lipid peroxidation induction. Theriogenology, 73: 1076-1087.

Turri F, Madeddu M, Gliozzi TM, Gandini G and Pizzi F. 2012. Influence of Recovery Methods and extenders on bull epididymal spermatozoa quality. Reprod. Domes. Ani., 47: 712-717.

Vernocchi V, Morselli MG, Varesi S, Nonnis S, Maffioli E, Negri A, Tedeschi G and Luvoni, GC. 2014. Sperm ubiquitination in epididymal feline semen. Theriogenology, 82: 636-642.

Yu I and Leibo SP. 2002. Recovery of motile, membrane-intact spermatozoa from canine epididymides stored for 8 days at 4 degrees C. Theriogenology, 57: 1179-1190. 